\title{
A Fast and Robust DC-Bus Voltage Control Method for Single-Phase Voltage-Source DC/AC Converters
}

\author{
Seyedfoad Taghizadeh, Student Member, IEEE, Masoud Karimi-Ghartemani, Senior Member, IEEE, \\ M. J. Hossain, Senior Member, IEEE, Junwei Lu, Senior Member, IEEE
}

\begin{abstract}
This paper presents a fast and robust dc-bus voltage control method for single-phase grid-connected dc/ac converters. The proposed technique precisely estimates the double-frequency (2-f) ripple of a dc-bus voltage and removes it from the voltagecontrol loop without adding any additional dynamics or oscillations. Conventionally, the 2-f ripple is managed by using large capacitors which increase the cost and bulkiness of a converter. As a state-of-the-art approach, a notch filter (NF) or a dc-voltage estimator is used to effectively block the 2-f ripple from the voltage-control loop, which can significantly reduce the capacitor size. However, such an approach introduces new dynamics in the control loop, causes additional oscillations on the bus voltage and increases the settling time of its response. This limits the degrees of freedom of the design to improve the overall system damping. The proposed method in this paper has no adverse impact on the original bus-voltage dynamic response. As a result, the bus-voltage control can be designed with higher speed and robustness and the whole system can operate with a reduced transient at both the bus voltage and the output ac current. The proposed approach is thoroughly analyzed and its effectiveness is validated through simulations and experimental results.
\end{abstract}

Index Terms - Double-frequency ripple, dc extraction, singlephase dc/ac converter, notch filter.

\section{INTRODUCTION}

$\mathrm{G}$ RID interconnection of low-power converter-based $\mathbf{J}_{\text {devices such as solar photovoltaic (PV) generators, single- }}$ phase electric-vehicle (EV) chargers and low-power rectifiers requires employment of single-phase voltage-source converters (VSCs) with adequate controls to properly respond to the input/output power exchange and voltage level [1-3]. The VSCs can also participate in grid ancillary services such as reactive power support, harmonics reduction and/or voltage regulation [4-6].

A typical control system of a single-phase grid-connected VSC comprises an outer voltage-control loop which is responsible for controlling the dc-bus voltage and an inner current-control loop that is used to control the grid-side current. Design of the control system for a single-phase VSC can

\footnotetext{
Seyedfoad Taghizadeh and M. J. Hossain are with the School of Engineering, Macquarie University, Australia. E-mail: s.t.taghizadeg@ieee.org, jahangir.hossain@mq.edu.au.

Junwei Lu is with the Department of Science and Engineering, Griffith University, Australia. E-mail: j.lu@griffith.edu.au.
}

become challenging, partly due to the double-frequency (2-f) ripple of the dc-bus voltage which is a natural byproduct of the single-phase ac/dc power conversion [7]. While the 2-f ripple is not removed, it can circulate from the outer voltage-control loop into the inner current-control loop through its input reference signal. As a result, such a disturbance appears on the grid-side current as a third harmonic and also as a shift from the desired reactive power [8].

A conventional practice is to increase the size of the passive bus component (dc-bus capacitor) that acts as an energy storage for the grid-side 2-f power. The dc-bus capacitor decouples the pulsation of the grid-side power and limits the amplitude of the 2 -f ripple within an acceptable range. Although this hardwarebased solution is effective, it decreases the lifetime and increases the cost and bulkiness of the converter $[9,10]$. As an alternative, an auxiliary circuit is used that draws constant current from the input and creates a high dc voltage to provide the needed pulsation at the output [10-13]. However, this method decreases the efficiency and increases the complexity of both the hardware and the control system.

A state-of-the-art approach is to use a software-based filter in the voltage-control loop. The filter prevents the 2-f ripple from penetrating into the control loop and spoiling its variables, without an unnecessary increase in the size of the dc-bus capacitor and without complicating the hardware [14, 15]. For instance, a second-order low-pass filter (LPF) is used in the voltage-control loop of a two-stage EV charger in [5]. The LPF appears to effectively attenuate the 2-f ripple, however, its operation exhibits a low convergence rate [15]. A third-order filter as a dc observer is introduced in [15] and operates with higher convergence speed. Nevertheless, this method has the drawback of high transient at a quick bus-voltage variation which may be caused by its redundant structure, i.e. using three differential equations for a system which can be designed at order of two. As another approach, a second-order notch filter (NF) is used to block the 2-f ripple from the voltage control of a single-phase VSC [14]. The NF exhibits an optimum response, higher convergence rate and lower transient than the other two aforementioned filters. Accordingly, the NF can be

Masoud Karimi-Ghartemani is with the Department of Electrical and Computer Engineering, Mississippi State University, E-mail: karimi@ece.msstate.edu. 
considered as the state of the art to tackle the 2-f ripple in a busvoltage control loop. An alternative way of implementing the $\mathrm{NF}$ is presented in [16] where it allowed to feedback the internal state variables of the NF to improve the transient responses of the entire control loop.

Although the steady-state performances of the abovementioned filters are acceptable and the bus-capacitor size can be reduced substantially, using an additional filter means adding more modes (poles) into a voltage-control loop. This can inevitably produce extra overshoots, oscillations and settling time and thus limit the flexibility of the design to improve the overall system damping. Consequently, the voltage-control loop is forced to be designed with a lower bandwidth in order to maintain the system transients within an acceptable range. This issue, which is not addressed in the literature, is the focus of this paper.

This paper proposes a novel idea of removing the 2-f ripple without adding any additional filter to the bus-voltage control loop, nor producing extra overshoots, oscillations and increased settling time to the control process. The novel bus-voltage control method is based on estimating and removing the 2-f ripple of the bus voltage through exploiting the operatingsystem parameters and variables. Accordingly, the dynamic response of the bus voltage is not affected and a much higher bandwidth can be achieved. The proposed method is simple in structure and shows a superior robustness and transient response (at both the dc-bus voltage and the output ac current) compared with the listed conventional bus-voltage control methods. The performance and damping improvement of the proposed approach are investigated and confirmed by analysis, computer simulations and experimental results.

\section{Conventional Bus-Voltage Control LoOP}

Figure 1 presents a typical diagram of a single-phase gridconnected device including the VSC, the dc-side source or load, the dc-bus capacitor, the grid-side inductor, and the grid. Figure 2 shows two conventional control structures for the VSC. Each one has an outer bus-voltage control loop and an inner currentcontrol loop. The two common current-control strategies are a proportional-resonant $(P R)$ controller in the time domain and proportional-integrating $(P I)$ controllers in the synchronous or direct-quadrature $(D Q)$ domain $[17,18]$.

In Fig. 2(a), the outer bus-voltage control loop generates the reference signal $I^{*}$ (which is ideally dc) for the inner currentcontrol loop. This reference is multiplied into a sinusoidal signal which is properly synchronized by the phase-locked loop (PLL) output angle $\theta$ plus the phase angle $\varphi$ (the required phase shift for reactive power). This forms the reference $i^{*}$ for the internal PR current controller. As shown, the phase shift $\varphi$ is calculated from $I_{\mathrm{q}}^{*}$, which is a user-defined parameter and is used to command a certain amount of reactive power as required for inductive/capacitive operation of the VSC. For a unity-power-factor operation, $\varphi$ is zero.

Figure 2(b) presents the block diagram of the VSC control when the internal current-control approach is the $P I$ or $D Q$ strategy. According to this method, the measured grid-side

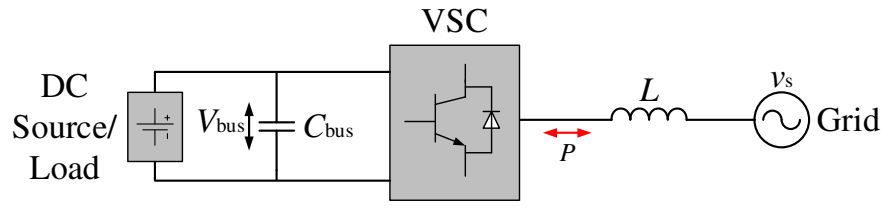

Fig. 1. Typical structure of a single-phase converter-based grid-connected device.

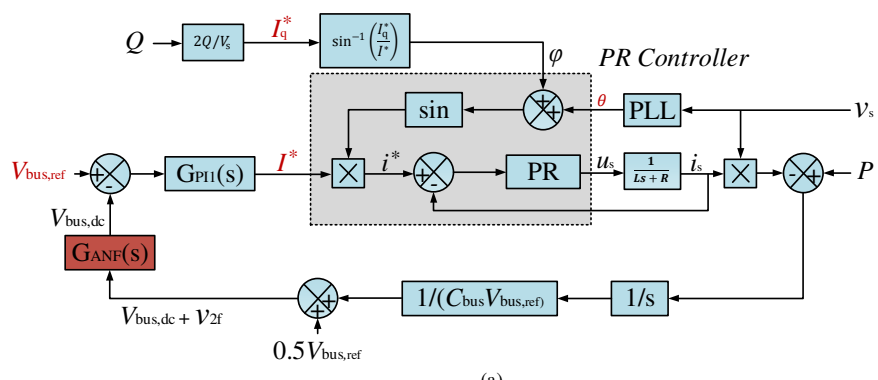

(a)

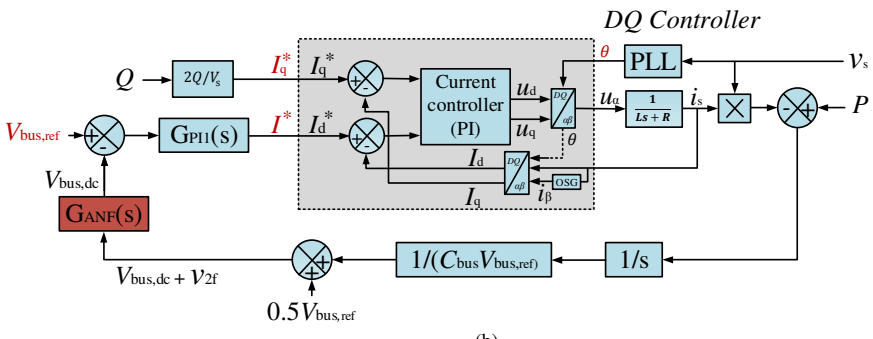

(b)

Fig. 2. Block diagram of a grid-connected VSC control. a) inner $P R$ current controller, b) inner PI current controller.

current $i_{\mathrm{s}}$ is transformed to the $D Q$ frame, $I_{\mathrm{d}}$ and $I_{\mathrm{q}}$ using the PLL angle. Then $I_{\mathrm{d}}$ and $I_{\mathrm{q}}$ are compared with the two reference signals $I_{\mathrm{d}}^{*}$ and $I_{\mathrm{q}}^{*}$, and the output errors are regulated to zero by the two PI controllers. As shown in Fig. 2(b), $I_{\mathrm{d}}^{*}$ is directly supplied by the outer bus-voltage control loop while $I_{\mathrm{q}}^{*}$ is a userdefined value and commands a certain amount of reactive power as required for inductive/capacitive operation of the VSC.

The NF on the bus-voltage feedback loops in both Figures 2(a) and 2(b) removes the 2-f ripple $v_{2 \mathrm{f}}$ from the voltagecontrol loop. This allows reduction of $C_{\text {bus }}$ without distorting the current reference. However, this tightens the limits of the controllers` (particularly $G_{\mathrm{PI}_{1}}(s)$ ) design and control bandwidth due to adding an additional filter $G_{\mathrm{ANF}}(s)$ which adds extra dynamics into the control loop and causes oscillatory responses during sharp transients.

According to the proposed idea in this paper, the 2-f ripple $v_{2 \mathrm{f}}$ can be eliminated without adding an extra filter to the feedback loop. The references $I^{*}$ (the output of the bus-voltage control loop), $V_{\text {bus,ref }}$ (the reference value of the bus voltage), $I_{\mathrm{q}}^{*}$ (the output of the reactive-power controller) and $\theta$ (PLL`s output) which are shown in red and are common in both control systems (Figures 2(a) and 2(b)) are used in a proposed algorithm to estimate $v_{2 \mathrm{f}}(t)$. Then, using a simple subtraction, $v_{2 \mathrm{f}}(t)$ can be removed from the feedback loop. As a result, $G_{\mathrm{ANF}}(s)$, which is a second-order filter, can be eliminated from the feedback loops and the whole control system can be redesigned with a higher bandwidth. 


\section{Proposed Bus-Voltage CONTROL LoOP}

\section{A. Derivation of the proposed dc-extraction method}

An actual bus voltage can be dominantly modeled as

$$
V_{\text {bus }}(t)=V_{\text {bus,dc }}+v_{2 \mathrm{f}}(t)
$$

in which $V_{\text {bus,dc }}$ is the dc offset and $v_{2 \mathrm{f}}(t)$ is the 2-f ripple as expressed by

$$
v_{2 \mathrm{f}}(t)=V_{2 \mathrm{f}} \sin (2 \theta+\varphi)
$$

where $\varphi$ is the phase shift between the grid voltage and current and $\theta$ is the grid-voltage phase angle.

In (2), $V_{2 f}$ which is the amplitude of the 2 -f ripple, can be expressed as

$$
V_{2 \mathrm{f}}=\frac{S}{2 C_{\mathrm{bus}} \omega V_{\mathrm{bus}, \mathrm{ref}}} .
$$

In (3), $C_{\text {bus }}$ is the bus capacitance, $V_{\text {bus,ref }}$ is the reference value of the bus voltage, and $S=\sqrt{P^{2}+Q^{2}}$ is the transferred ac apparent power, where $P$ and $Q$ are the active and reactive powers.

In the control systems of a VSC, which are shown in Figures 2(a) and 2(b), the output signal of the outer bus-voltage control loop $I^{*}$ and $I_{\mathrm{q}}^{*}$ can be used to estimate the 2-f ripple of the bus voltage $v_{2 \mathrm{f}}(t)$ (i.e., $\hat{v}_{2 \mathrm{f}}(t)$ ) according to

$$
\hat{v}_{2 \mathrm{f}}(t)=\frac{\sqrt{\hat{P}^{2}+\widehat{Q}^{2}}}{2 C_{\text {bus }} \omega V_{\text {bus }, \mathrm{dc}}} \sin (2 \psi+\gamma)
$$

where

$$
\hat{P}=\frac{1}{2} V_{\mathrm{S}} I^{*}, \hat{Q}=\frac{1}{2} V_{\mathrm{S}} I_{\mathrm{q}}^{*}, \gamma=\sin ^{-1}\left(\frac{I_{\mathrm{q}}^{*}}{I^{*}}\right) .
$$

The PLL is used to estimate the grid-side voltage phase angle $[19,20]$. When the PLL operates in the steady-state mode, $\psi$ in (4) will become equal to $\theta$ in (2). The PLL also supplies $V_{s}$, which is the peak value of the gird voltage. Moreover, as the PR in Fig. 2(a) and the two PI controllers in Fig. 2(b) eliminate the steady-state errors between the measured and reference signals, eventually $\hat{v}_{2 \mathrm{f}}(t)$ becomes equal to $v_{2 \mathrm{f}}(t)$. Therefore, the proposed method uses $I^{*}, I_{\mathrm{q}}^{*}, V_{\mathrm{s}}, V_{\mathrm{bus}, \text { ref }}$ and $\theta$ to estimate $\hat{v}_{2 \mathrm{f}}(t)$, and thus (1) is rearranged in the form of (6) to extract $V_{\text {bus,dc }}$ from $V_{\text {bus }}(t)$ as

$$
V_{\text {bus,dc }}=V_{\text {bus }}(t)-\hat{v}_{2 \mathrm{f}}(t)
$$

The block diagram of the proposed method is shown in Fig. 3. According to the proposed dc-extraction algorithm (Fig. 3) and the VSC control structures in Figures 2(a) and 2(b), the operation of the proposed method is independent of the type of the internal current controller ( $P R$ controller or $D Q$ controller). However, in this paper, the system in Fig. 2(b) is implemented and the proposed algorithm (Fig. 3) is applied and tested accordingly.

\section{Design Aspects of Proposed AND CONVENTIONAL NF- BASED APPROACHES}

\section{A. Studied system}

Figure 4 shows a simplified linear time-invariant (LTI) model of a VSC controller that includes the voltage-control loop, the current-control loop (D-axis) and the plant which represents a single-phase grid-connected VSC with an L filter. The inner current-control loop is shown by $L_{1}$ and the whole

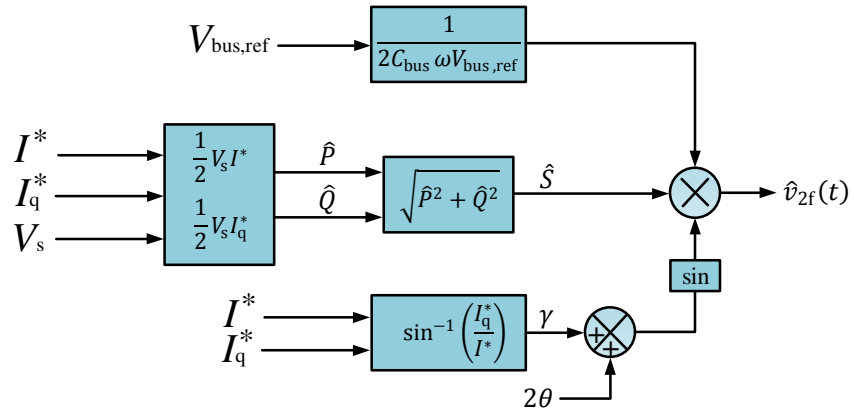

Fig. 3. Block diagram of the proposed dc-extraction method.
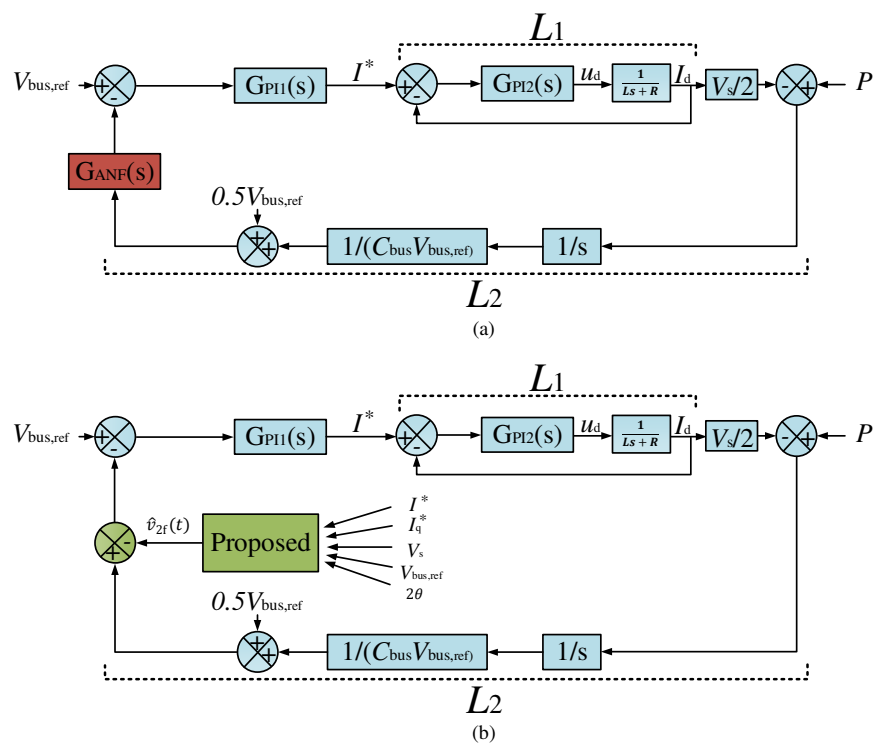

Fig. 4. LTI model of a VSC controller. a) conventional NF-based approach, b) proposed approach.

control loop is presented by $L_{2}$. This model is used in this paper to design the inner current-control loop, the outer voltagecontrol loop using a conventional NF (Fig. 4(a)), and the outer voltage-control loop using the proposed dc-extraction method (Fig. 4(b)). $G_{\mathrm{ANF}}$ in Fig. 4(a) represents the transfer function of the second-order NF as given by

$$
G_{\mathrm{ANF}}(s)=\frac{s^{2}+4 \omega^{2}}{s^{2}+4 \zeta \omega s+4 \omega^{2}}
$$

where $\zeta$ is the damping ratio of the poles and $\omega$ is the angular frequency.

\section{B. Design of inner current-control loop for selecting $k_{2}$ and $\tau_{2}$}

In this section, the design process of the inner current-control loop $\left(L_{1}\right)$ is presented. The transfer function of the loop $L_{1}$ is expressed as

$$
H_{L 1}(s)=\frac{G_{\mathrm{PI} 2}(s)\left(\frac{1}{L s+R}\right)}{1+G_{\mathrm{PI} 2}(s)\left(\frac{1}{L s+R}\right)} .
$$

The current controller is designed to be fast enough to avoid interactions with the outer loop. The gains of $G_{\mathrm{PI} 2}(s)$ are selected using the procedure presented in [21]. According to this method, the gains of $G_{\mathrm{PI} 2}(s), k_{2}$ and $\tau_{2}$ are selected using the system`s model in Figures 4(a) or 4(b). For this analysis, the 
plant is assumed to be $\frac{1}{L S+R}$ which represents a practical inductor. Following that, the pole of the plant is placed at $-\frac{R}{L}$ and can be cancelled by the zero of $G_{\mathrm{PI} 2}(s)=k_{2}\left(1+\frac{1}{\tau_{2} s}\right)$. Then, using the system parameters of Table $\mathrm{I}$, where $R=12$ $\mathrm{m} \Omega$, the gain $\tau_{2}$ of $G_{\mathrm{PI} 2}(s)$ can be determined by $\tau_{2}=\frac{L}{R}=350$ ms. Now while selecting $k_{2}=25$, the pole of the loop $L_{1}$ will be placed at $\frac{k_{2}}{L}=5952$ which is less than half of the selected switching frequency $(13 \mathrm{kHz})$ and is in an appropriate location. The designed $k_{2}=25$ and $\tau_{2}=350 \mathrm{~ms}$, which ensure fast operation of the current-control loop, are used throughout this paper for analysis, simulation and experimental tests.

\section{Design of conventional NF-based voltage-control loop for selecting $\tau_{1}$}

This section presents the integral gain $\left(\tau_{1}\right)$ selection for $G_{\mathrm{PI} 1}(s)$ in Fig. 4(a), where the conventional NF is applied to the voltage-control loop. The characteristic equation of $L_{2}$ in Fig. 4(a) is given by

$1-k_{1} \frac{V_{s}}{2 C_{\text {bus }} V_{\text {bus }, \text { ref }}}\left(1+\frac{1}{\tau_{1} s}\right) \frac{1}{s} H_{L 1}(s) G_{A N F}(s)=0$

where $k_{1}$ and $\tau_{1}$ are the gains of $G_{\mathrm{PI} 1}(s)$.

According to the design procedure of a bus-voltage control loop in [14], $\tau_{1}$ is supposed to be as small as possible. This achieves higher bandwidth for the bus-voltage control loop and thus a lower fluctuation of the bus voltage. Figure 5 shows the loci of the poles of the conventional method, given by (9), versus different values of $\tau_{1}=12.5 \mathrm{~ms}, 10 \mathrm{~ms}, 7.5 \mathrm{~ms}$ and $5 \mathrm{~ms}$. As shown, the intersection point of the loci with the real axis shifts toward the left as $\tau_{1}$ decreases from $12.5 \mathrm{~ms}$ to $10 \mathrm{~ms}$, which means a possible reduction in the fluctuation of the bus voltage. However, as shown, for smaller $\tau_{1}(7.5 \mathrm{~ms}$ and $5 \mathrm{~ms})$, the form of the root locus changes and the roots change their trajectory toward the unstable region. This means that, using the conventional method, the minimum $\tau_{1}$ cannot be smaller than $10 \mathrm{~ms}$ where the intersection of the roots with the real axis is guaranteed. Accordingly, using this analysis, $\tau_{1}=10 \mathrm{~ms}$ is selected as the designed gain in this paper to implement the conventional system.

\section{Design of proposed voltage-control loop for selecting $\tau_{1}$}

Using the proposed method shown in Fig. 4(b), there is more flexibility in selecting $\tau_{1}$. The characteristic equation for the proposed method given by $L_{2}$ in Fig. 4(b) is expressed as

$$
1-k_{1} \frac{V_{\mathrm{s}}}{2 C_{\mathrm{bus}} V_{\text {bus,ref }}}\left(1+\frac{1}{\tau_{1} s}\right) \frac{1}{s} H_{L 1}(s)=0 .
$$

Figure 6 shows the loci of the roots of (10) versus different values of $\tau_{1}=12.5 \mathrm{~ms}, 10 \mathrm{~ms}, 7.5 \mathrm{~ms}$ and $5 \mathrm{~ms}$. As can be seen, unlike the conventional NF method, reducing $\tau_{1}$ does not change the form of the loci, therefore smaller $\tau_{1}$ can be selected and the bus-voltage control loop can be designed with lower fluctuation. Using this analysis, $\tau_{1}=5 \mathrm{~ms}$ is selected as the designed gain in this paper to implement the proposed system.
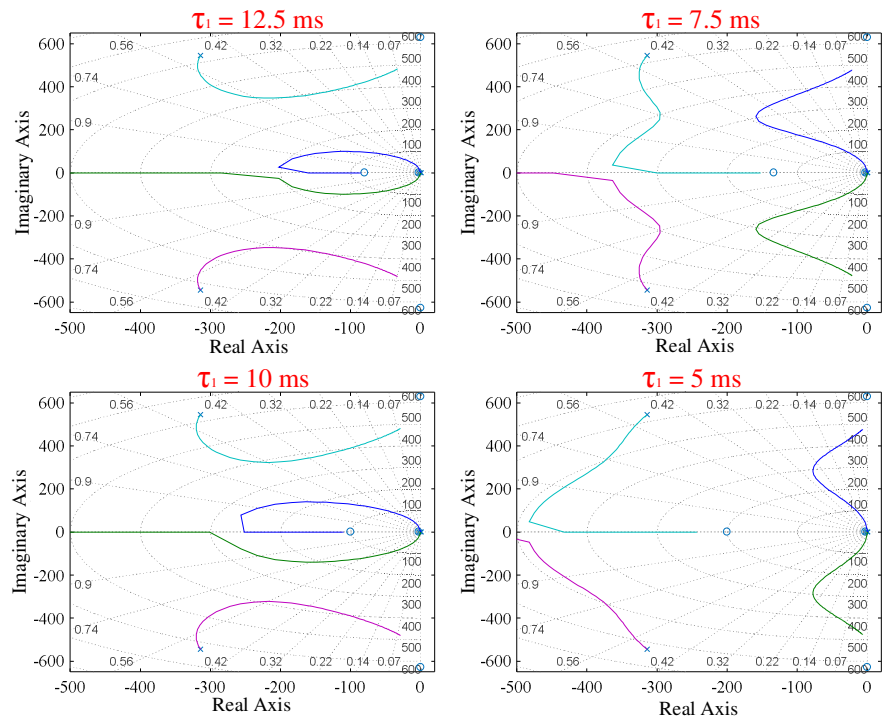

Fig. 5. Loci of the roots of (9) versus different values of $\tau_{1}=12.5 \mathrm{~ms}, 10 \mathrm{~ms}$, $7.5 \mathrm{~ms}$ and $5 \mathrm{~ms}$ when $\zeta=0.5$.
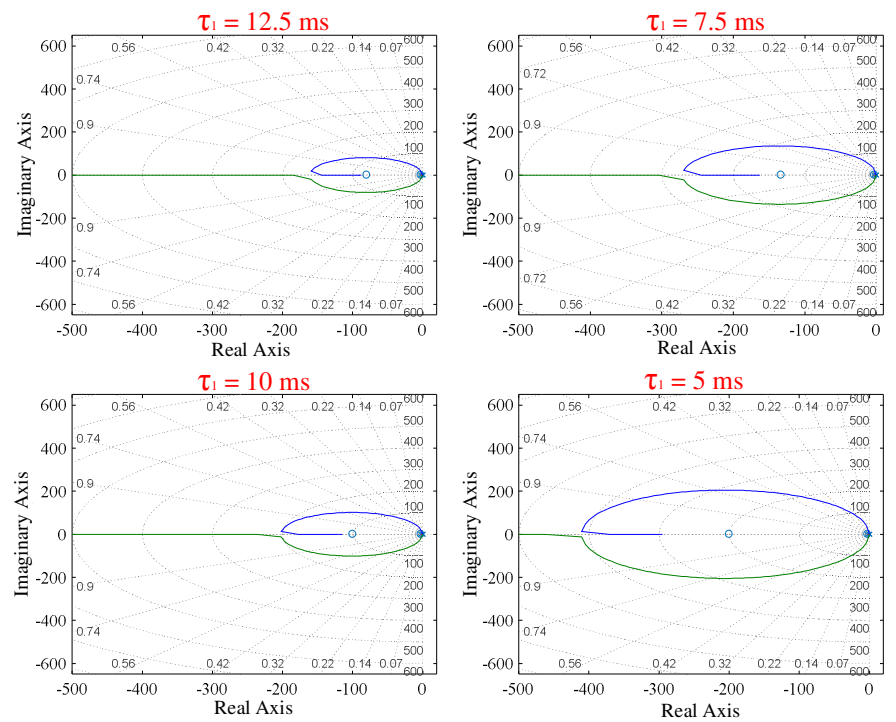

Fig. 6. Loci of the roots of (10) versus different values of $\tau_{1}=12.5 \mathrm{~ms}, 10 \mathrm{~ms}$, $7.5 \mathrm{~ms}$ and $5 \mathrm{~ms}$.

\section{E. Proportional gain selection $k_{1}$ for the proposed and conventional NF-based voltage-control loops}

Figure 7(a) shows the loci of the conventional method (9) using the designed $\tau_{1}=10 \mathrm{~ms}$. As $k_{1}$ increases from zero, the two upper and lower poles move toward the right side. At the same time, their damping reduces remarkably. For instance, at $k_{1}=0.2$, the roots show 0.29 damping corresponding to $38 \%$ overshoot. This means that the value of $k_{1}$ must be selected to be as small as possible for the conventional method. Otherwise, the bus voltage will experience a large overshoot and oscillations. Such a phenomenon is shown in Fig. 8(a).

On the other hand, using the proposed method, the larger $k_{1}$ contributes to higher damping while increasing the stability margin of the bus-voltage control loop at the same time. This, in the form of loci, is shown in Fig. 7(b). At the same $k_{1}=0.2$, the root exhibits 0.68 damping corresponding to $5 \%$ overshoot. The dynamic of the bus voltage itself is shown in Fig. 8(b). 


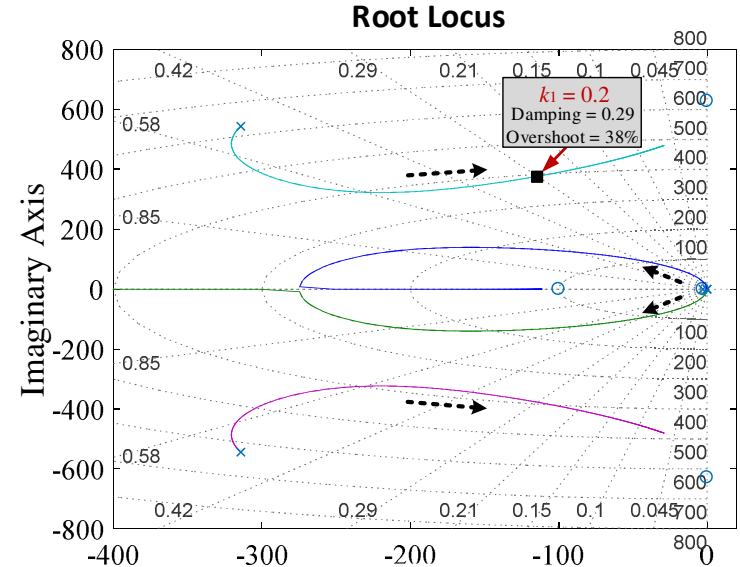

(a)

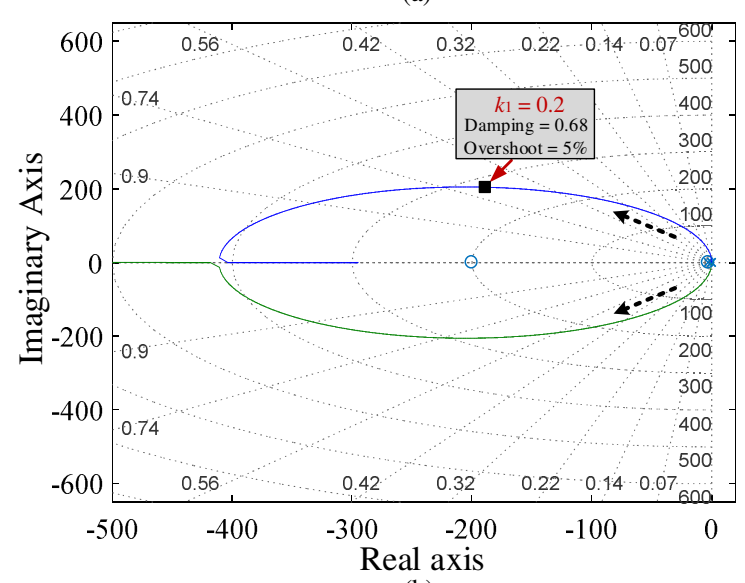

(b)

Fig. 7. Loci of the roots of (9) and (10). a) conventional method when $\tau_{1}=10$ $\mathrm{ms}$, and $\zeta=0.5, \mathrm{~b}$ ) proposed method when $\tau_{1}=5 \mathrm{~ms}$.
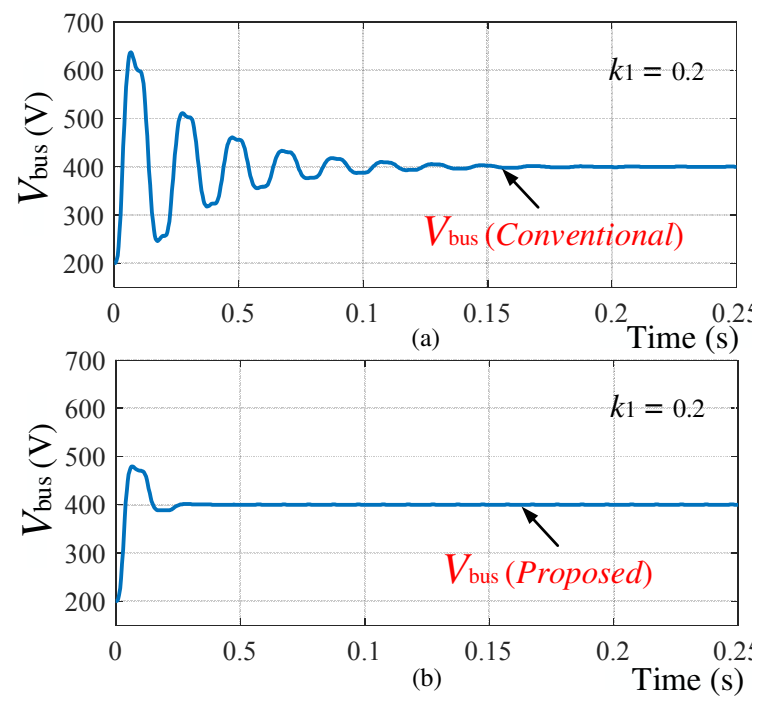

Fig. 8. Comparing the dynamics of bus voltage $V_{\text {bus }}$ when the proposed and conventional methods are tuned with the same gain $k_{1}=0.2$. a) bus voltage using the conventional method, b) bus voltage using the proposed method.

It should be noted that, although the higher value of $k_{1}$ shows better performance according to the loci in Fig. 7(b), $k_{1}>0.35$ is not recommended. The reason is that a larger $k_{1}$ can amplify noises of the system and allow them to pollute the bus-voltage control loop.
TABLE I. SYSTEM PARAMETERS

\begin{tabular}{c|cc}
\hline \hline \multicolumn{1}{c}{ Circuit Parameter } & Item & Value \\
\hline$v_{\mathrm{s}}$ & AC line voltage & $220 \mathrm{~V}(\mathrm{RMS})$ \\
$V_{\text {bus }}$ & DC-bus voltage & $400 \mathrm{~V}$ \\
$f$ & Line frequency & $50 \mathrm{~Hz}$ \\
$f_{\text {sw }}$ & Switching frequency & $13 \mathrm{kHz}$ \\
$L$ & Filter inductor & $4.2 \mathrm{mH}$ \\
$R$ & Filter resistor & $12 \mathrm{~m} \Omega$ \\
$C_{\text {bus }}$ & DC-bus capacitor & $220 \mu \mathrm{F}$ \\
\hline \hline Control Parameters & Item & Value \\
(Proposed System) & Gains of $G_{\mathrm{PI} 1}(s)$ & $-0.2,5 \mathrm{~ms}$ \\
$k_{1}, \tau_{1}$ & Gains of $G_{\mathrm{PI} 2}(s)$ & $25,350 \mathrm{~ms}$ \\
$k_{2}, \tau_{2}$ & Gains of $G_{\mathrm{PI} 3}(s)$ & $25,350 \mathrm{~ms}$ \\
$k_{3}, \tau_{3}$ & Item & Value \\
\hline \hline Control Parameters & Gains of $G_{\mathrm{PI} 1}(s)$ & $-0.08,10 \mathrm{~ms}$ \\
$($ Conventional NF System) & Gains of $G_{\mathrm{PI} 2}(s)$ & $25,350 \mathrm{~ms}$ \\
$k_{1}, \tau_{1}$ & Gains of $G_{\mathrm{PI} 3}(s)$ & $25,350 \mathrm{~ms}$ \\
$k_{2}, \tau_{2}$ & NF Damping ratio & 0.5 \\
$k_{3}, \tau_{3}$ &
\end{tabular}

Using the performed analysis, in order to achieve the best response from both the proposed and conventional NF methods, $k_{1}=0.2$ and $\tau_{1}=5 \mathrm{~ms}$ are selected for the proposed method and $k_{1}=0.08$ and $\tau_{1}=10 \mathrm{~ms}$ are selected for the conventional method. Thus, the designed gains for the conventional system and for the proposed system will be used for the rest of the analysis, simulation and experimental results in this paper.

Table I summarizes the systems parameters.

\section{ANALYSIS, COMPARISON AND DISCUSSION}

\section{A. Comparison using pole-zero location versus changing $\zeta$}

The transfer function of the whole closed loop $\left(L_{2}\right)$ in Fig. 4(a) for the conventional NF method from $P_{\text {in }}$ to $V_{\text {bus }}$ is $H_{\mathrm{c}}(s)=\frac{V_{\text {bus }}}{P_{\text {in }}}$

$$
=\frac{\left(\frac{1}{s}\right)\left(\frac{1}{C_{\mathrm{bus}} V_{\mathrm{bus}, \mathrm{ref}}}\right) G_{\mathrm{ANF}}(s)}{1+G_{\mathrm{PI} 1}(s) H_{L 1}(s)\left(V_{\mathrm{s}} / 2\right)(1 / s)\left(1 / C_{\mathrm{bus}} V_{\mathrm{bus}, \mathrm{ref}}\right) G_{\mathrm{ANF}}(s)} \text {. }
$$

After simplifying, (11) forms a transfer function of order 5.

The whole closed-loop transfer function of the proposed method from $V_{\text {bus,ref }}$ to $P_{\text {in }}$ is

$$
\begin{aligned}
& H_{\mathrm{c}}(s)=\frac{V_{\text {bus }}}{P_{\text {in }}} \\
& =\frac{(1 / s)\left(1 / C_{\text {bus }} V_{\text {bus }, \text { ref }}\right)}{1+G_{\text {PI } 1}(s) H_{L 1}(s)\left(V_{\mathrm{s}} / 2\right)(1 / s)\left(1 / C_{\text {bus }} V_{\text {bus }, \text { ref }}\right)}
\end{aligned}
$$

which is a transfer function of order 3 . Figure 9 compares the pole-zero map of the closed-loop proposed system and the conventional NF versus different values of $0.1<\zeta<0.7$ which is the damping factor of the conventional NF.

The analysis shown in Fig. 9 concludes that the NF's damping ratio $\zeta$ should not be small (to avoid poor damping of high-frequency poles) and should not be large (to avoid poor damping of low-frequency poles). Therefore a value of $0.4<\zeta$ $<0.6$ is recommended and $\zeta=0.5$ is selected for the rest of this study. The approximate settling time can be calculated from

$$
t_{\mathrm{s}} \approx \frac{4}{\gamma \omega_{\mathrm{n}}}
$$

where $\gamma$ is defined as the closed-loop poles`s damping ratio and 


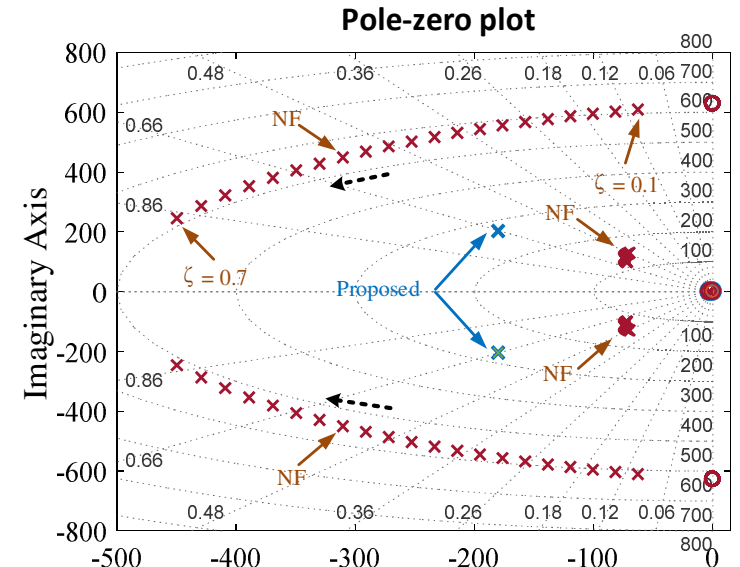

(a)

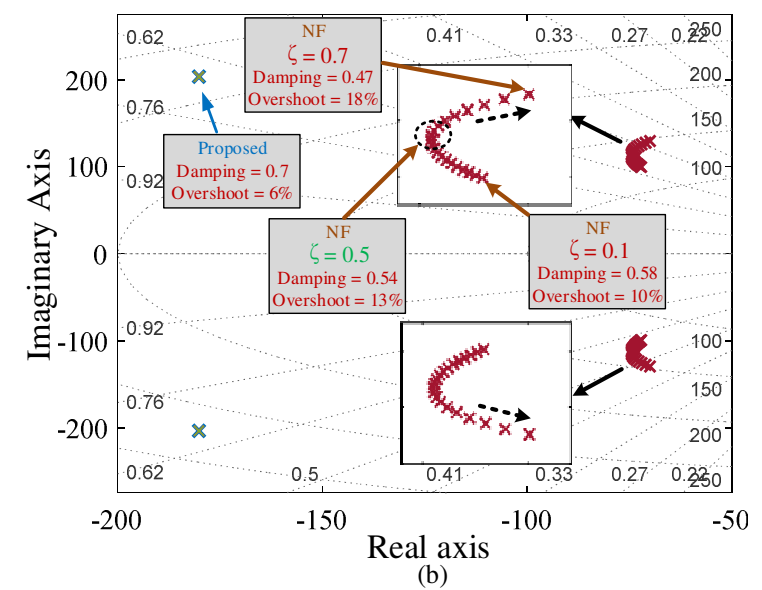

Fig. 9. Pole-zero plot of the closed-loop systems. a) showing the whole plot, b) zoomed to show the dominant poles.

$\omega_{\mathrm{n}}$ is their natural frequency. Solving the characteristic equation of (10) results in the equation $s^{2}+2 \gamma \omega_{\mathrm{n}}+\omega_{\mathrm{n}}{ }^{2}=0$, where $\gamma$ and $\omega_{\mathrm{n}}$ are defined by

$$
\begin{gathered}
2 \gamma \omega_{\mathrm{n}}=-k \frac{V_{\mathrm{s}}}{2 C_{\text {bus }} V_{\text {bus, ref }}} \\
\omega_{\mathrm{n}}{ }^{2}=-k \frac{V_{\mathrm{s}}}{2 C_{\mathrm{bus}} V_{\text {bus,ref } \tau} \tau}=\frac{2 \gamma \omega_{\mathrm{n}}}{\tau} .
\end{gathered}
$$

Then substituting the designed $k_{1}=0.2$ and $\tau_{1}=5 \mathrm{~ms}$ for the proposed method along with the other system parameters of Table I, $\omega_{\mathrm{n}}$ for the proposed method is calculated at $265 \mathrm{rad} / \mathrm{s}$ from (15). Accordingly, the settling time $t_{\mathrm{s}}$ is approximately 21 $\mathrm{ms}$ from (13) for the pole`s damping ratio of $\gamma=0.7$, which is shown in Fig. 9(b). Similarly, using the designed $k_{1}=0.08$ and $\tau_{1}=10 \mathrm{~ms}$ for the conventional NF method and the other system parameters of Table I, $\omega_{\mathrm{n}}=119 \mathrm{rad} / \mathrm{s}$ for the conventional method. Accordingly, $t_{\mathrm{s}}$ is calculated for the two indicated poles with $\zeta=0.1$ and $\zeta=0.7$ in Fig. 9(b). At $\zeta=0.1$, which corresponds to the pole`s damping ratio of $\gamma=0.58$, the settling time is estimated from (13) as $t_{\mathrm{s}} \approx 57 \mathrm{~ms}$. In addition, at $\zeta=0.7(\gamma=0.47)$, the settling time is $t_{\mathrm{s}} \approx 71 \mathrm{~ms}$. As mentioned before, $\zeta$ for the conventional method is designed to be 0.5 . Therefore, at $\zeta=0.5$ the dominant poles shown in Fig. 9(b) have a damping ratio of $\gamma=0.54$ and a settling time of $t_{\mathrm{s}} \approx 62 \mathrm{~ms}$.

It can be seen that the proposed method achieves a substantial
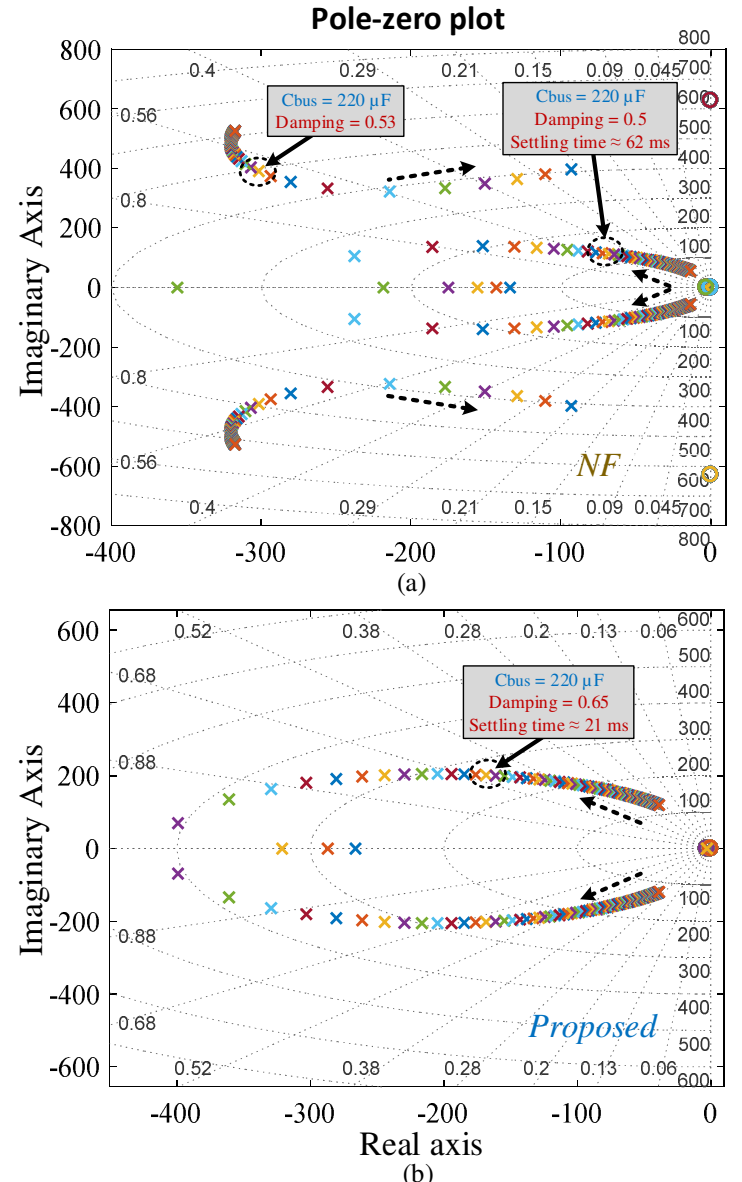

Fig. 10. Trajectory of system poles when $C_{\text {bus }}$ reduces from $1 \mathrm{mF}$ to $75 \mu \mathrm{F}$ with an step of $25 \mu \mathrm{F}$. a) conventional NF, b) proposed method.

improvement in the settling time $\left(t_{\mathrm{s}} \approx 21 \mathrm{~ms}\right)$ compared with the conventional method $\left(t_{\mathrm{s}} \approx 62 \mathrm{~ms}\right)$.

\section{B. Comparison using pole-zero location versus changing $C_{\text {bus }}$}

Figure 10 compares the pole-zero map of the conventional $\mathrm{NF}$ and the proposed method when $C_{\mathrm{bus}}$ reduces from $1 \mathrm{mF}$ to $75 \mu \mathrm{F}$ with a step change of $25 \mu \mathrm{F}$. As can be seen in Fig. 10(a), the upper and lower dominant poles of the conventional method move toward the imaginary axis (lower damping) as $C_{\text {bus }}$ reduces. On the other hand, in Fig. 10(b), the damping of the dominant poles of the proposed method increases as $C_{\text {bus }}$ decreases. In this paper, $C_{\mathrm{bus}}=220 \mu \mathrm{F}$ is used for the design and implementation of both the proposed and the conventional methods. As can be seen, at $C_{\text {bus }}=220 \mu \mathrm{F}$, the conventional method has two pairs of dominant poles and each one exhibits approximately 0.5 damping. However, the proposed system has one pair of dominant poles, placed at the better damping position of 0.65 . This verifies the lower fluctuation of the bus voltage using the proposed system. The settling time of the conventional method is shown as $t_{\mathrm{s}} \approx 62 \mathrm{~ms}$ using (13) while the proposed method exhibits $t_{\mathrm{s}} \approx 21 \mathrm{~ms}$.

Table II shows the poles and zeros of both the proposed and the conventional NF methods (Figures 4(a) and 4(b)) when they are designed based on the procedure explained in Sections IV and $\mathrm{V}$. 


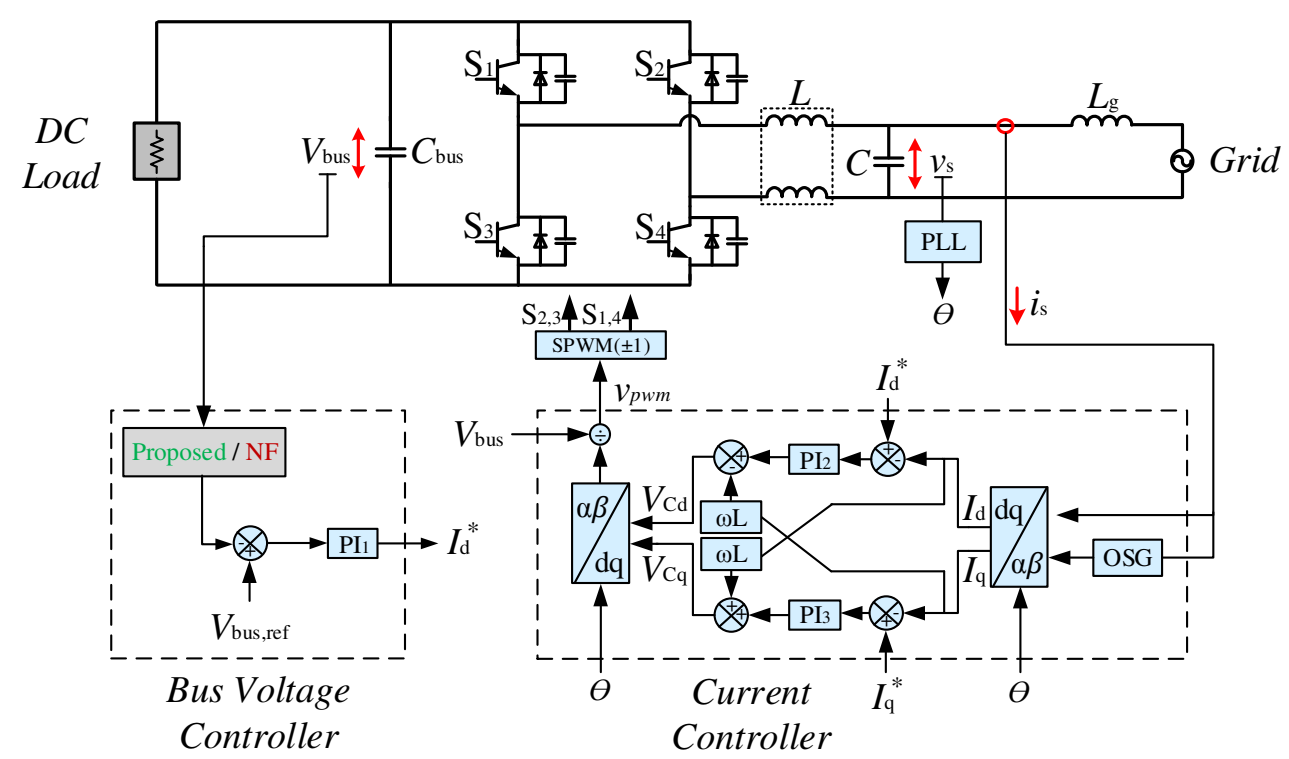

Fig. 11. Overall system topology including the power circuit and the control system.

Table II. CLOSED LOOP POLES OF THE PROPOSED AND THE CONVENTIONAL NF SYSTEMS.

\begin{tabular}{c|c|c|c|c}
\hline \hline No. & $\begin{array}{c}\text { Closed-loop } \\
\text { zeros } \\
\text { (Proposed) }\end{array}$ & $\begin{array}{c}\text { Closed-loop } \\
\text { poles } \\
\text { (Proposed) }\end{array}$ & $\begin{array}{c}\text { Closed-loop } \\
\text { poles } \\
\text { (Conventional } \\
\text { NF) }\end{array}$ & $\begin{array}{c}\text { Closed-loop } \\
\text { zeros } \\
\text { (Conventional } \\
\text { NF) }\end{array}$ \\
\hline \hline 1 & 0 & -5589.3 & -5792.4 & 0 \\
\hline 2 & -5952.4 & $-181.5+$ & -319.9 & -5952.4 \\
\hline 3 & & $-181.5-$ & $-319.9-$ & $628.3 \mathrm{i}$ \\
\hline 4 & & $205.8 \mathrm{i}$ & $440.2 \mathrm{i}$ & $-628.3 \mathrm{i}$ \\
\hline 5 & & & $-74.3+$ & $117.7 \mathrm{i}$ \\
\hline
\end{tabular}

\section{Vi. Performance Evaluation of Proposed Method}

In this section, the dynamic responses and steady-state performance of the proposed control method are evaluated and compared with the conventional NF in [14], using both simulations in MATLAB Simulink and experimental results. The proposed method and the conventional NF, which are designed in Section IV and V, are implemented and compared in a single-stage grid-connected rectifier as shown in Fig. 11. The parameters in Table I are used for both simulations and experiments.

\section{A. Performance evaluation via simulation results}

The tests are performed under two conditions: i) during step changes of the bus-voltage command, and ii) during step changes of the input power (load switching). Figure 12(a) shows the bus voltage $V_{\text {bus }}$ using the proposed and the conventional NF during a step change of $400 \mathrm{~V} \rightarrow 500 \mathrm{~V}$. Figure 12(b) presents $V_{\text {bus }}$ during a step change of $500 \mathrm{~V} \rightarrow$ $400 \mathrm{~V}$. As can be seen, when the proposed voltage-control method is used, $V_{\text {bus }}$ exhibits lower overshoot, oscillations and settling time during the step changes. As theoretically calculated in Section V-A, the settling time of the bus voltage is supposed to be $21 \mathrm{~ms}$ for the proposed method and $62 \mathrm{~ms}$ for
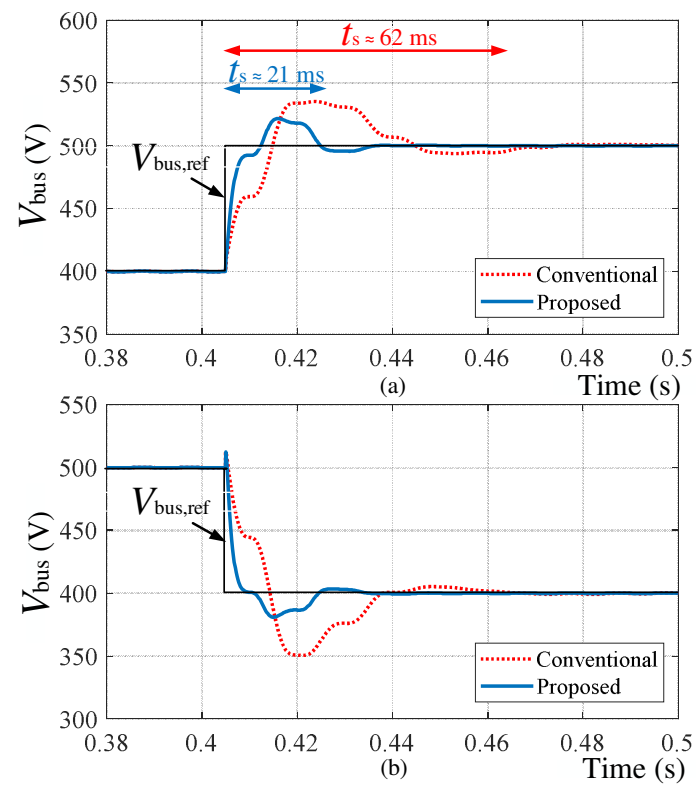

Fig. 12. Dynamic performance comparison during bus-voltage variation. a) $V_{\text {bus }}$ $=400 \mathrm{~V} \rightarrow 500 \mathrm{~V}$, b) $V_{\text {bus }}=500 \mathrm{~V} \rightarrow 400 \mathrm{~V}$.

the conventional NF, which are almost consistent with the simulation results in Figures 12(a) and 12(b). This validates the performed analysis as well as the superior performance of the proposed method than the conventional NF.

In another test, the dynamic response of $V_{\text {bus }}$ is evaluated during load variation while $V_{\text {bus }}$ is fixed at $400 \mathrm{~V}$. Figure 13(a) shows the bus voltage $V_{\text {bus }}$ and the extracted dc using the proposed method, and Fig. 13(b) shows the grid-side current $i_{s}$, when the power $P$ increases from $10 \mathrm{~W}$ to $1000 \mathrm{~W}$. Figure 14(a) presents $V_{\text {bus }}$ and Fig. 14(b) presents $i_{\mathrm{s}}$ using the conventional NF. As can be seen, both the proposed and the conventional methods can successfully extract the dc component of $V_{\text {bus }}$. However, when the proposed method is applied, $V_{\text {bus }}$ and $i_{\mathrm{s}}$ in Fig. 13 exhibit lower transient and settling time than $V_{\text {bus }}$ and $i_{\mathrm{s}}$ in Fig. 14, which presents the dynamic response of the conventional method. 

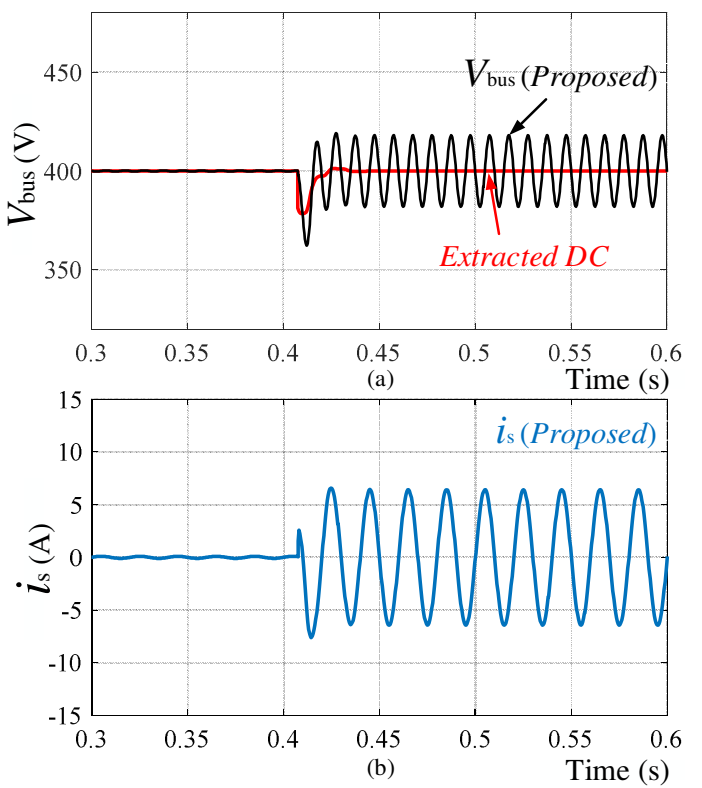

Fig. 13. Dynamic performance of the proposed method during load variation $P=10 \mathrm{~W} \rightarrow 1000 \mathrm{~W}$.
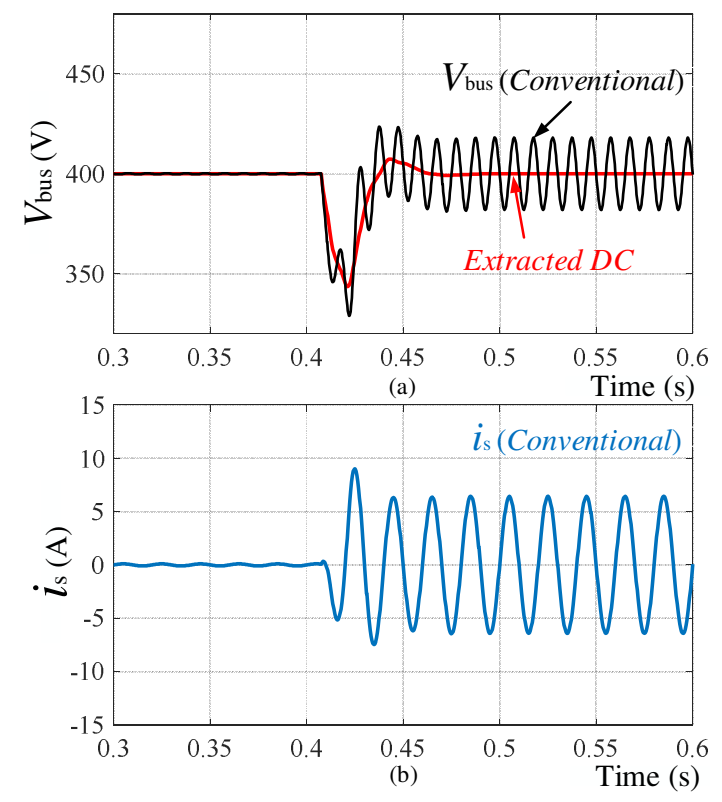

Fig. 14. Dynamic performance of the conventional method during load variation $P=10 \mathrm{~W} \rightarrow 1000 \mathrm{~W}$.

Figure 15 shows the transient response of $V_{\text {bus }}$ and $i_{\mathrm{s}}$ during a load switching from $P=1000 \mathrm{~W}$ to $10 \mathrm{~W}$ using the proposed method. Figure 16 presents the results of a similar test when the conventional method is applied. As can be seen, a lower transient is achieved on both $V_{\text {bus }}$ and $i_{\mathrm{s}}$ in Fig. 15, validating the better performance of the proposed approach.

Comparing the simulation results of the proposed method and the conventional method validates the robustness of the proposed approach in term of removing the 2-f ripple, and its superior performance in improving the overall system damping. Such a salient feature is validated using experimental tests in the following section.
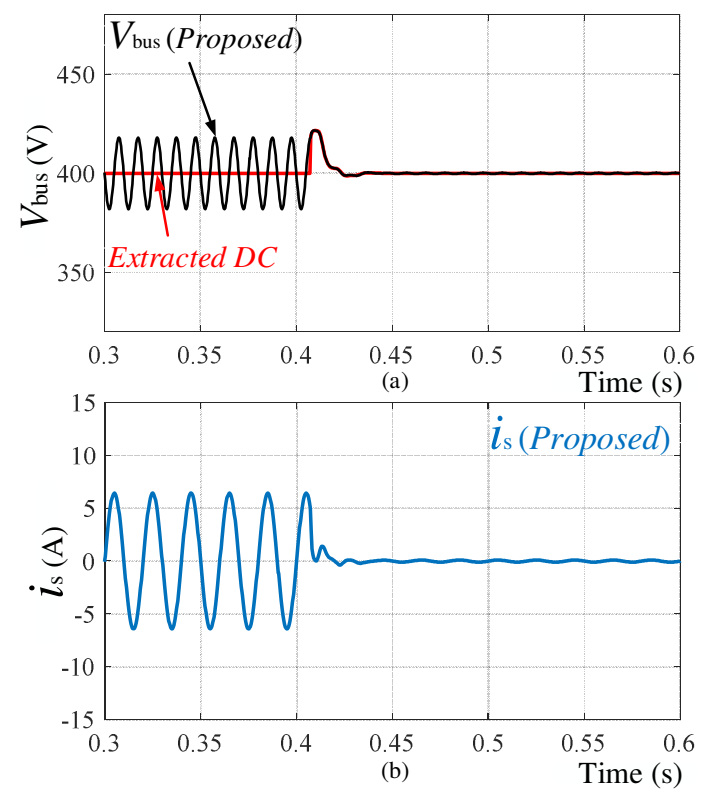

Fig. 15. Dynamic performance of the proposed method during load variation $P=1000 \mathrm{~W} \rightarrow 10 \mathrm{~W}$.
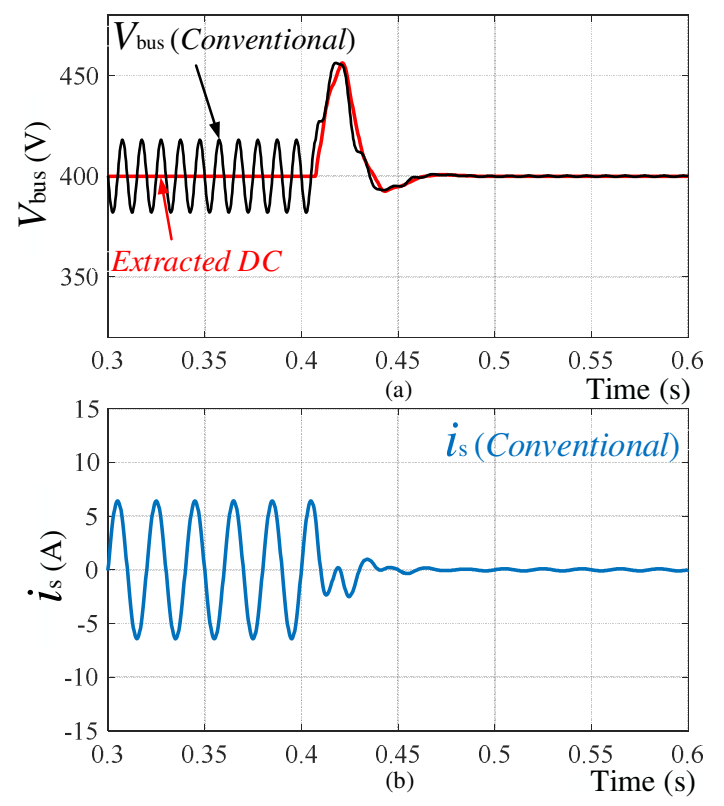

Fig. 16. Dynamic performance of the conventional method during load variation $P=1000 \mathrm{~W} \rightarrow 10 \mathrm{~W}$.

\section{B. Performance evaluation via experimental results}

A laboratory prototype of the single-phase rectifier shown in Fig. 11 is implemented and tested in the grid-connected mode. The system parameters in Table I are used for this purpose. A SEMISTACK - IGBT as the ac/dc grid-connected VSC, a RS Pro 8.14 kVA Variac, a Chroma 63800 electronic load, and an MI 2883EU Class S power quality analyzer are used for the experimental testing. The proposed method and the conventional NF in [14], that designed in Section IV and V, are implemented on a TMSF28335 controller via programing in Clanguage, and the dynamic performance of $V_{\mathrm{bus}}$ and $i_{\mathrm{s}}$ are compared using similar tests to that used in simulation. 


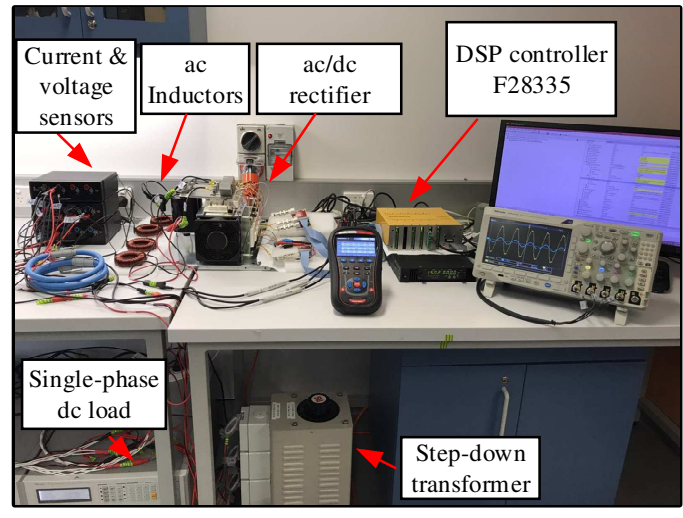

Fig. 17. Experimental setup.

Figure 18 shows a bus voltage $V_{\text {bus }}$ startup when $V_{\text {bus,ref }}$ is set to $200 \mathrm{~V}$. Figure $18(\mathrm{a})$ shows $V_{\text {bus }}$ and $i_{\mathrm{s}}$ when the conventional NF is used in the bus-voltage control loop and Fig. 18 (b) shows $V_{\text {bus }}$ and $i_{\mathrm{s}}$ when the proposed method is applied. Although the two methods show appropriate responses in regulating $V_{\text {bus }}$, the proposed method exhibits lower transients and higher robustness than the conventional NF. As shown, the settling time of $V_{\text {bus }}$ in the conventional method is measured at around $t_{\mathrm{s}}=80 \mathrm{~ms}$, which is close to the theoretical value of $t_{\mathrm{s}}=62 \mathrm{~ms}$ in Section V-A. On the other hand, using the proposed method $t_{\mathrm{s}}$ is reduced to about $35 \mathrm{~ms}$ that can also validate the theoretical $t_{\mathrm{s}}=21 \mathrm{~ms}$. It should be noted that the differences between the measured settling times and the theoretical values are because of the non-linearities and uncertainties of the system which are neglected in the theoretical analysis in Section V-A.

Figure 19 compares the dynamics of both $V_{\text {bus }}$ and $i_{\mathrm{s}}$ using both the conventional NF and the proposed method during a quick load variation from $P=0$ to $700 \mathrm{~W}$ while $V_{\text {bus,ref }}$ is set to $200 \mathrm{~V}$. As shown, the conventional method exhibits a higher transient (undershoot) and settling time $\left(t_{\mathrm{s}}=70 \mathrm{~ms}\right)$ than the proposed method $\left(t_{\mathrm{s}}=25 \mathrm{~ms}\right)$. This test also shows the better performance of the VSC (in Fig. 11) when the proposed method is used. The result of this test revalidates the simulation results in Figures 13 and 14.

In the last test, the disturbance of a load switching is tested with $P=700 \rightarrow 0 \mathrm{~W}$ and the performance of the VSC is tested using both the conventional NF and the proposed method. As can be seen in Fig. 20(a), the quick load disconnection generates a substantial transient on $V_{\text {bus }}$ which would be harmful for the bus capacitor $C_{\text {bus }}$. However, as Fig. 20(b) presents, when VSC uses the proposed method, this transient will be significantly lower. This test also confirms the robustness and better dynamic response of the proposed approach while revalidating the simulation results in Figures 15 and 16.

It should be noted that all the simulation and experimental tests are performed when the proposed and conventional methods are designed to achieve their best performance. The design process is already explained individually for both the conventional and the proposed method in Sections IV and V and the outcomes are summarized in Table I via showing the gains of the PI controllers. Accordingly, it is concluded that the

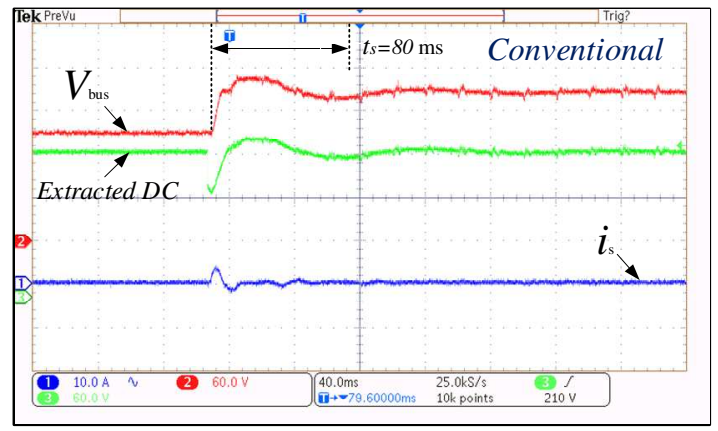

(a)

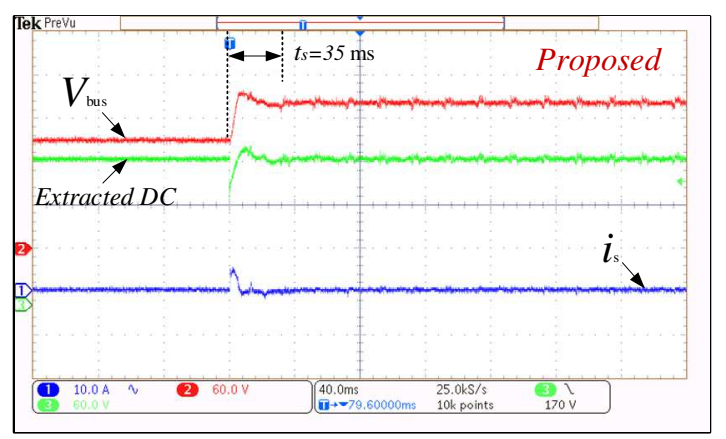

(b)

Fig. 18. Experimental results of the dynamic response during the bus-voltage startup. Grid-side current $i_{\mathrm{s}}(\mathrm{Ch} .110 \mathrm{~A} / \mathrm{div})$, bus voltage $V_{\text {bus }}(\mathrm{Ch} .260 \mathrm{~V} / \mathrm{div})$, and the extracted dc of $V_{\text {bus }}(\mathrm{Ch} .360 \mathrm{~V} /$ div). a) conventional NF [14], b) proposed method.

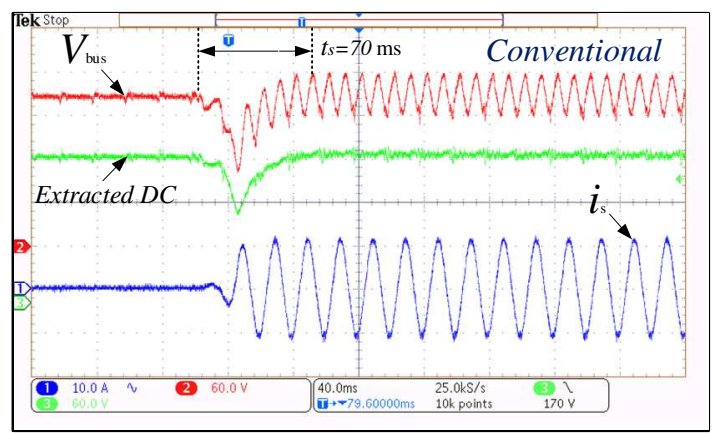

(a)

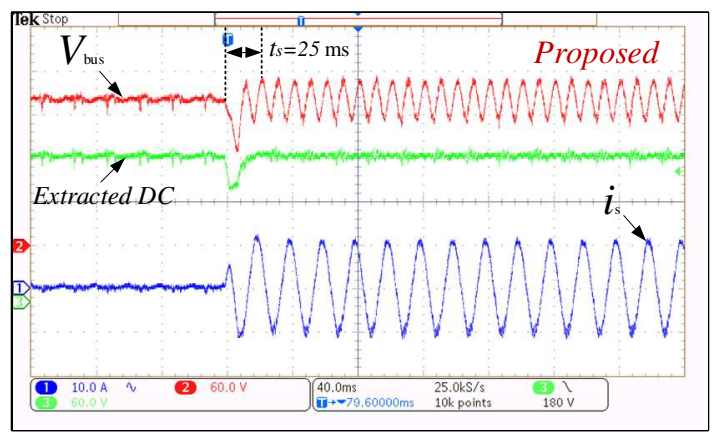

(b)

Fig. 19. Experimental results of the dynamic response during a load variation from $P=0 \mathrm{~W} \rightarrow 700 \mathrm{~W}$. Grid-side current $i_{\mathrm{s}}(\mathrm{Ch} .110 \mathrm{~A} / \mathrm{div})$, bus voltage $V_{\text {bus }}$ $(\mathrm{Ch} .260 \mathrm{~V} / \mathrm{div})$, and the extracted dc of $V_{\text {bus }}(\mathrm{Ch} .360 \mathrm{~V} / \mathrm{div})$. a) conventional NF [14], b) proposed method.

voltage-control loop that uses the conventional NF must be designed at a lower bandwidth via tuning $G_{\mathrm{PI} 1}(s)$ with gains $k_{1}=0.08$ and $\tau_{1}=10 \mathrm{~ms}$, whereas when the proposed method is used, a higher bandwidth can be targeted via tuning $G_{\mathrm{PI} 1}(s)$ with higher gains $k_{1}=0.2$ and $\tau_{1}=5 \mathrm{~ms}$. In other words, when 


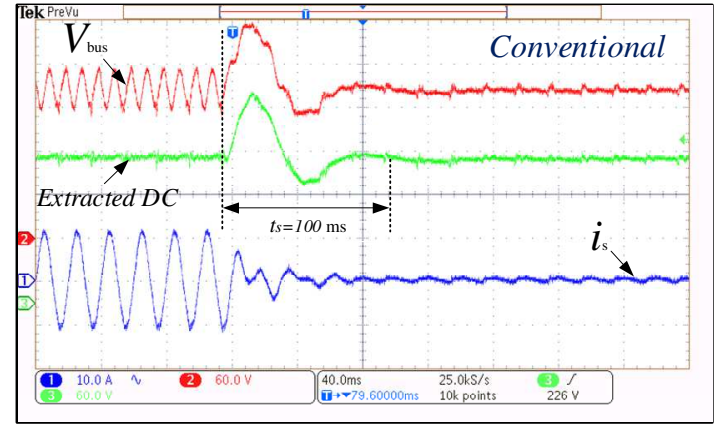

(a)

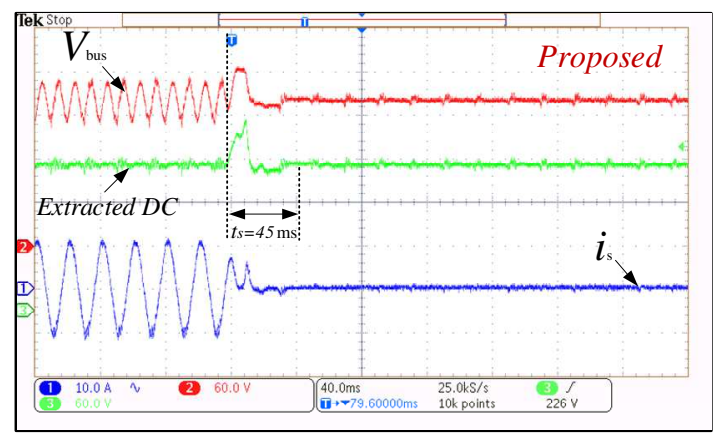

(b)

Fig. 20. Experimental results of the dynamic response during a load variation from $P=700 \mathrm{~W} \rightarrow 0 \mathrm{~W}$. Grid-side current $i_{\mathrm{s}}(\mathrm{Ch} .110 \mathrm{~A} / \mathrm{div})$, bus voltage $V_{\text {bus }}$ (Ch.2 $60 \mathrm{~V} / \mathrm{div})$, and the extracted dc of $V_{\text {bus }}(\mathrm{Ch} .360 \mathrm{~V} / \mathrm{div})$. a) conventional NF [14], b) proposed method.

the NF is added to the voltage-control loop, a fast tuning of $G_{\mathrm{PI} 1}(s)$ (high bandwidth) is not possible and would shift the system toward the poor damping area. This is the disadvantage of the conventional method as verified in Fig. 7 and the simulation results presented in Fig. 8. Figure 21 shows this fact when the conventional method is also tuned with the fast tuning of the proposed method ( $k_{1}=0.2$ and $\left.\tau_{1}=5 \mathrm{~ms}\right)$. As can be seen, this tuning (higher bandwidth) causes larger oscillations on $V_{\text {bus }}$ in Fig. 21(a) while the proposed method is remarkably robust and stable as shown in Fig. 21(b).

\section{CONCLUSION}

This paper presents a novel dc-bus voltage control method for single-phase grid-connected VSCs. The proposed method estimates the 2-f ripple of a bus voltage and removes it from the control loop directly without adding any filter, nor affecting the dynamics of the bus-voltage control system. While the proposed method is used, the 2-f ripple is precisely eliminated and the voltage-control loop can be designed with a higher bandwidth, which would be an asset for a VSC to exhibit higher robustness against common disturbances such as bus-voltage variations and/or quick load changing. The proposed method is compared with the conventional NF-based method and its superior performance is validated through mathematical analysis, simulation in MATLAB Simulink and experimental results.

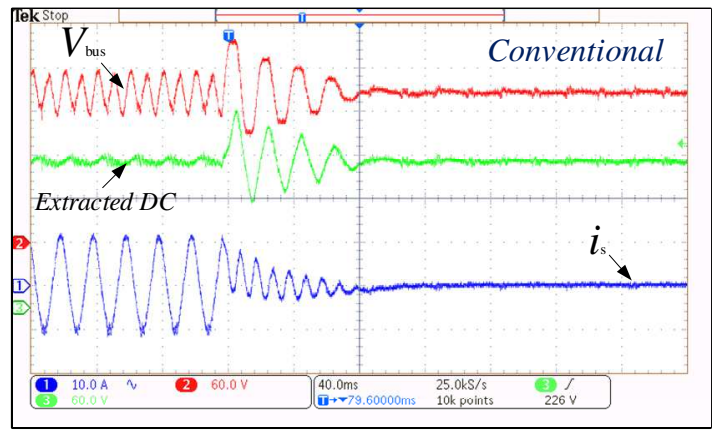

(a)

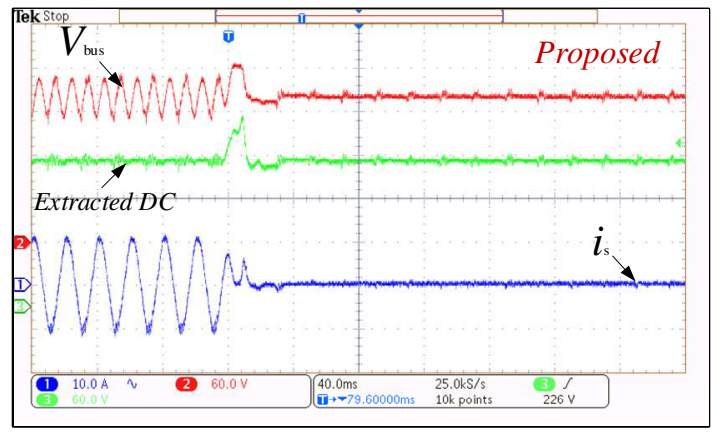

(b)

Fig. 21. Experimental results of the dynamic response during a load variation from $P=700 \mathrm{~W} \rightarrow 0 \mathrm{~W}$ when the same design of the proposed voltage-control loop is used for the conventional method. Grid-side current $i_{\mathrm{s}}($ Ch.1 $10 \mathrm{~A} / \mathrm{div})$, bus voltage $V_{\text {bus }}(\mathrm{Ch} .260 \mathrm{~V} / \mathrm{div})$, and the extracted dc of $V_{\text {bus }}(\mathrm{Ch} .360 \mathrm{~V} / \mathrm{div})$. a) conventional NF [14], b) proposed method.

\section{REFERENCES}

[1] Y. Xue, L. Chang, S. B. Kjaer, J. Bordonau, and T. Shimizu, "Topologies of single-phase inverters for small distributed power generators: an overview," IEEE Transactions on Power Electronics, vol. 19, no. 5, pp. 1305-1314, 2004.

[2] S. B. Kjaer, J. K. Pedersen, and F. Blaabjerg, "A review of single-phase grid-connected inverters for photovoltaic modules," IEEE transactions on industry applications, vol. 41, no. 5, pp. 1292-1306, 2005.

[3] V. Monteiro, J. Pinto, and J. L. Afonso, "Operation modes for the electric vehicle in smart grids and smart homes: present and proposed modes," IEEE Transactions on Vehicular Technology, vol. 65, no. 3, pp. 1007$1020,2016$.

[4] J. Maza-Ortega, A. Gomez-Exposito, M. Barragan-Villarejo, E. Romero-Ramos, and A. Marano-Marcolini, "Voltage source converterbased topologies to further integrate renewable energy sources in distribution systems," IET Renewable Power Generation, vol. 6, no. 6, pp. 435-445, 2012.

[5] M. C. Kisacikoglu, M. Kesler, and L. M. Tolbert, "Single-phase onboard bidirectional PEV charger for V2G reactive power operation," IEEE Transactions on Smart Grid, vol. 6, no. 2, pp. 767-775, 2015.

[6] S. Taghizadeh, M. Hossain, J. Lu, and W. Water, "A unified multifunctional on-board EV charger for power-quality control in household networks," Applied Energy, vol. 215, pp. 186-201, 2018.

[7] P. T. Krein, R. S. Balog, and M. Mirjafari, "Minimum energy and capacitance requirements for single-phase inverters and rectifiers using a ripple port," IEEE Transactions on Power Electronics, vol. 27, no. 11, pp. 4690-4698, 2012.

[8] M. Karimi-Ghartemani, S. A. Khajehoddin, P. Jain, and A. Bakhshai, "A systematic approach to DC-bus control design in single-phase gridconnected renewable converters," IEEE Transactions on Power Electronics, vol. 28, no. 7, pp. 3158-3166, 2013.

[9] S. B. Kjaer, J. K. Pedersen, and F. Blaabjerg, "Power inverter topologies for photovoltaic modules-a review," in Industry Applications Conference, 2002. 37th IAS Annual Meeting. Conference Record of the, 2002, vol. 2, pp. 782-788: IEEE.

[10] T. Shimizu, K. Wada, and N. Nakamura, "Flyback-type single-phase utility interactive inverter with power pulsation decoupling on the DC 
input for an AC photovoltaic module system," IEEE transactions on power electronics, vol. 21, no. 5, pp. 1264-1272, 2006.

[11] Y. Sun, Y. Liu, M. Su, W. Xiong, and J. Yang, "Review of active power decoupling topologies in single-phase systems," IEEE Transactions on Power Electronics, vol. 31, no. 7, pp. 4778-4794, 2016.

[12] M. A. Vitorino, L. F. S. Alves, R. Wang, and M. B. de Rossiter Corrêa, "Low-frequency power decoupling in single-phase applications: A comprehensive overview," IEEE Transactions on Power Electronics, vol. 32, no. 4, pp. 2892-2912, 2017.

[13] R. Chen, Y. Liu, and F. Z. Peng, "DC capacitor-less inverter for singlephase power conversion with minimum voltage and current stress," IEEE Transactions on Power Electronics, vol. 30, no. 10, pp. 54995507, 2015.

[14] S. A. Khajehoddin, M. Karimi-Ghartemani, P. K. Jain, and A. Bakhshai, "DC-bus design and control for a single-phase grid-connected renewable converter with a small energy storage component," IEEE Transactions on Power Electronics, vol. 28, no. 7, pp. 3245-3254, 2013.

[15] M. Pahlevani and P. Jain, "A fast DC-bus voltage controller for bidirectional single-phase AC/DC converters," IEEE Transactions on power electronics, vol. 30, no. 8, pp. 4536-4547, 2015.

[16] S. Taghizadeh, J. Hossain, J. Lu, and M. Karimi-Ghartemani, "An Enhanced DC-Bus Voltage Control Loop for Single-Phase Gridconnected DC/AC Converters," IEEE Transactions on Power Electronics, 2018.

[17] D. Dong, T. Thacker, R. Burgos, F. Wang, and D. Boroyevich, "On zero steady-state error voltage control of single-phase PWM inverters with different load types," IEEE Transactions on Power Electronics, vol. 26, no. 11, pp. 3285-3297, 2011.

[18] B. Li, S. Huang, X. Chen, and S. Wan, "Enhanced dq current control for single-phase voltage-source inverters," IET Power Electronics, 2018.

[19] M. Karimi-Ghartemani, "Linear and pseudolinear enhanced phasedlocked loop (EPLL) structures," IEEE transactions on industrial electronics, vol. 61, no. 3, pp. 1464-1474, 2014.

[20] M. Karimi-Ghartemani, "Synchronous Reference Frame PLL," Enhanced Phase-Locked Loop Structures for Power and Energy Applications, pp. 133-145, 2014

[21] M. Ebrahimi, S. A. Khajehoddin, and M. Karimi-Ghartemani, "Fast and robust single-phase DQ current controller for smart inverter applications," IEEE Transactions on Power Electronics, vol. 31, no. 5, pp. 3968-3976, 2016.

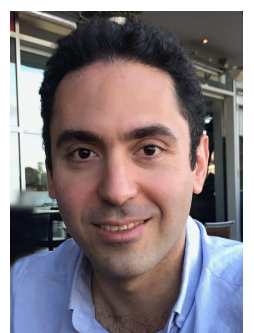

Seyedfoad Taghizadeh received his M.Sc. degree in Electrical and Electronic Engineering from the Universiti Tenaga Nasional (UNITEN), Malaysia, in 2013. He is currently working toward the Ph.D. degree in School of Engineering, Macquarie University, Australia. His research interests include electric vehicle chargers, control systems, renewable energy integration, power quality, and energy storage systems.

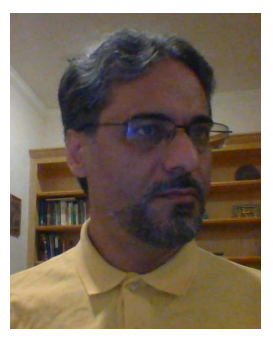

Masoud Karimi Ghartemani (SM'09) received the Ph.D. degree in Electrical and Computer Engineering from the University of Toronto, Canada, in 2004. $\mathrm{He}$ was a faculty member with the Electrical Engineering Department at Sharif University of Technology, Tehran, during 2005 and 2008. Was a member of the ePOWER laboratory, Queen's University during 2008 and 2011. Since 2012, he has been an Associate Professor with the Electrical and Computer Engineering Department at the Mississippi State University, USA. His general research area is power system analysis, stability, and control. His current interest is focused on the integration of distributed and renewable energy systems and the challenges pertaining to the modeling and control of such systems at high grid penetration level.

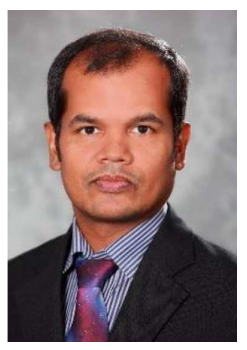

M. Jahangir Hossain (M'10-SM'13) received the B.Sc. and M.Sc. Eng. degrees from Rajshahi University of Engineering and Technology (RUET), Bangladesh, in 2001 and 2005, respectively, and the Ph.D. degree from the University of New South Wales, Australia, all in electrical and electronic engineering. He is currently an Associate Professor with the Department of Engineering, Macquarie University. Before joining there, he served as a Senior Lecture and a Lecturer in the Griffith School of Engineering, Griffith University, for five years and as a Research Fellow in the School of Information Technology and Electrical Engineering, University of Queensland, Brisbane, Australia. His research interests include renewable energy integration and stabilization, voltage stability, micro grids and smart grids, robust control, electric vehicles, flexible ac transmission systems devices, and energy storage systems.

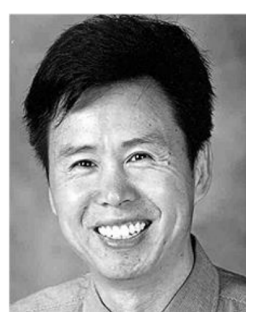

Junwei Lu (M'95-SM'05) received the degree in electrical engineering from Xian Jiaotong University, China and the M.Eng. degree in electronic and computer engineering from the National Toyama University, Japan, and the Ph.D. degree in electrical and computer engineering from the National Kanazawa University, Japan, in 1991. From 1976 to 1984, he worked with the electrical power industry (now is called State Grid) in China, where he was involved in the various national research projects for electrical power industry. In 1985, his academic study and research was in the area of computational electromagnetics at the laboratory of electrical communication engineering at Toyama University, Japan. In 1988, he has worked on the applied computational electromagnetics and was involved in the development of magnetics devices with the Laboratory of Electrical Energy Conversion, Kanazawa University. He joined the new School of Microelectronic Engineering, at Griffith University, Brisbane, Australia, in 1992, and moved to Gold Coast campus to establish a new department of Electrical and Electronic Engineering as a Foundation Professor since 2011. His fields of interest are computational electromagnetics, EMC computer modeling and simulation, high-frequency magnetics for power electronics and renewable energy system. His current research interests include smart transformer and V2G with built-in d-statcom inverter, smart hybrid AC/DC Microgrid. He has published over 250 journal and conference papers and three coauthored books in the area of computational electromagnetics for nonlinear electromagnetic fields, EMC computer modeling and simulation, and V2G linking smart grid, and holds over 10 international patents related smart antennas and high frequency transformers. 